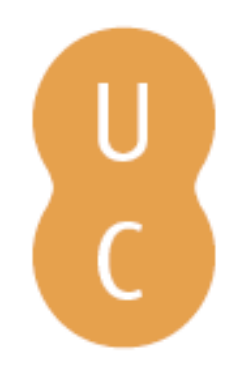

\title{
pompalina
}

\section{A Ética no contexto epistemológico da ciência da informação}

Autor(es): $\quad$ Araújo, Eliany Alvarenga de; Bezerra, Marcos Antonio Alexandre

Publicado por: Imprensa da Universidade de Coimbra

URL

persistente:

URI:http://hdl.handle.net/10316.2/31893

DOI:

DOI:http://dx.doi.org/10.14195/978-989-26-0319-3_19

Accessed : $\quad$ 26-Apr-2023 09:02:47

A navegação consulta e descarregamento dos títulos inseridos nas Bibliotecas Digitais UC Digitalis, UC Pombalina e UC Impactum, pressupõem a aceitação plena e sem reservas dos Termos e Condições de Uso destas Bibliotecas Digitais, disponíveis em https://digitalis.uc.pt/pt-pt/termos.

Conforme exposto nos referidos Termos e Condições de Uso, o descarregamento de títulos de acesso restrito requer uma licença válida de autorização devendo o utilizador aceder ao(s) documento(s) a partir de um endereço de IP da instituição detentora da supramencionada licença.

Ao utilizador é apenas permitido o descarregamento para uso pessoal, pelo que o emprego do(s) título(s) descarregado(s) para outro fim, designadamente comercial, carece de autorização do respetivo autor ou editor da obra.

Na medida em que todas as obras da UC Digitalis se encontram protegidas pelo Código do Direito de Autor e Direitos Conexos e demais legislação aplicável, toda a cópia, parcial ou total, deste documento, nos casos em que é legalmente admitida, deverá conter ou fazer-se acompanhar por este aviso. 
Maria Manuel Borges

Elias Sanz Casado

Coordenação

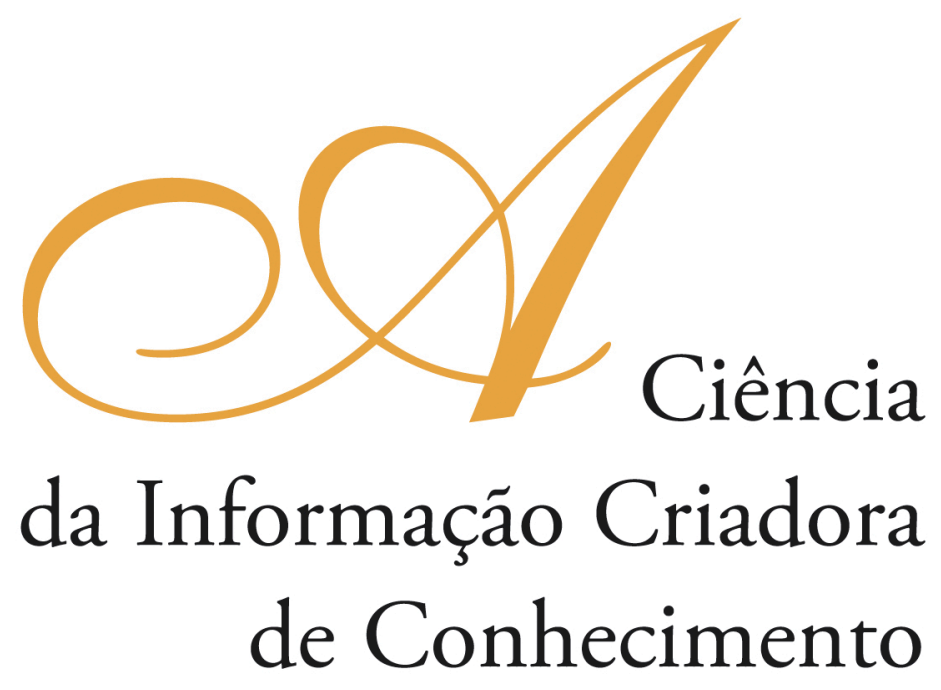

Vol. I

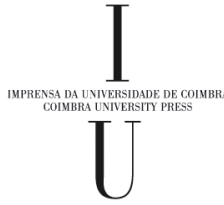

- COIMBRA 2009 


\title{
A ÉTICA No CONTEXTO EPISTEMOLÓGICO DA CIÊNCIA DA INFORMAÇÁO
}

\author{
Eliany Alvarenga de Araújo \\ Universidade Federal de Goiás (Brasil) \\ Marcos Antonio Alexandre Bezerra \\ Universidade Federal da Paraíba (Brasil)
}

\section{Resumo}

As expressivas mudanças que vêm se desenvolvendo na sociedade (globalização, Internet, sociedade da informaçáo e do conhecimento, etc) tem criado impactos significativos no campo epistemologico da Ciência da Informação. Tais impactos acabam chegando ao campo da ética e geram indagaçôes relativas as concepçôes de "bem agir", "bem fazer" ou "dever-ser". A partir destas consideraçôes surge uma indagação inicial que orienta nossas reflexões: Que valores éticos podem ser observados no atual contexto epistemológico da Ciência da Informação? A partir desta indagação poderemos buscar no campo da Ética da Informação algumas importantes indicaçóes que nos possibilitem desenhar possíveis respostas. Assim, se a ética é a teoria ou a explicação da experiencia humana considerando a totalidade/diversidade da mesma em termos de valores e normas morais, a Ética da Informação é o campo que tenta mediar os diferentes aspectos e conflitos oriundos da relação entre a informação e a liberdade humana baseada na reciprocidade de direitos. Esta colocaçáo nos revela a dimensão existencial do nosso estado de convivencia e de uso de informaçáo. Diante destas colocaçóes buscamos na Epistemologia Histórica de Bachelard o apoio reflexivo necessário para desenvolvermos nosso texto. Conforme este pensador o conhecimento é concebido como um "produçáo histórica", daí termos a necessidade de nos apoiarmos numa "filosofia aberta e móvel" que nega o método permanente e definitivo. Assim, cada ciência deve produzir, a cada momento de sua historia, suas próprias normas de verdade e os critérios de sua existencia. A delimitação de campo deste estudo se deu partir de dois momentos históricos da Ciência da Informação: a origem deste campo e a vinculação do mesmo aos desenvolvimentos tecnológicos. A partir deste recorte metodológico esperamos avançar em conhecimento sobre os atuais valores, normas e critérios de existencia da Ciência da Informaçáo, buscando com isto, compreender e ampliar nossa compreensão sobre a epistemologia deste campo.

\begin{abstract}
The expressive changes that are taking place in the society (Globalization, Internet, information and knowledge society, etc.) have brought about significant impacts on the epistemological field of Information Science. Those impacts have arrived to the field of ethics and have generated questions about the conceptions of "doing rightly", "doing well" or "must be". From these considerations arises an initial question, which orientates our reflections: Which ethics values can be noted in the current epistemological context of Information Science? From this question, we will be able to seek some important indications, in the field of Information Ethics, which
\end{abstract}


enables us to design possible answers. Thus, if ethics is the theory or the explanation of human experience, considering its totality/diversity in terms of moral values and rules, Information Ethics is the field that tries to mediate the different aspects and conflicts arising from the relation between information and human freedom, based on the reciprocity of rights. This collocation shows us the existential dimension of our living together condition and the use of information. With these positions we have sought in Bachelard's Historical Epistemology the reflexive support needed to develop our text. According to this thinker, knowledge is thought as a "historical production" therefore, the necessity to look for support on an "open and mobile philosophy", which denies the permanent and definitive method. So, each science has to produce, in every moment of its history, its own rules of truth, and the criteria for its existence. The boundary of the field of this study originated from two historical moments of the Information Science: the origin of this field and its entailing to technological developments. From this methodological clipping we hope to advance in knowledge on the present values, rules and criteria of existence of the Information Science, that way, looking for understanding and enlarge our knowledge about epistemology of this field.

\section{Introdução:}

A origem da Ciencia da Informação relaciona-se diretamente com os processos de comunicação científica. Para entendermos esta afirmação devemos considerar que a Ciencia Moderna, criada no século 16, e institucionalizada e consolidada nos seculos 17 e 18, gerou uma dinâmica informacional muito expressiva, devido a necessidade de se comunicar as descobertas, compartilhar medotologias e técnicas desenvolvidas e promover a divulgação e o registros dos conhecimentos científicos arduamente obtidos. Esta dinâmica informacional adquire padróes mundiais, a partir do seculo 20 (principalmente a partir da década de 60) e envolve a comunidade científica em discussóes acirradas sobre as possibilidades de se gerenciar o "caos documentário" oriundo da explosão bibliográfica.

Em termos de registro oficial da origem da Ciência da Informação, temos como fato histórico a famosa reunião ocorrida em 1962, na Georgia Institute of Technology, no Estados Unidos da América do Norte. O contexto em que este evento ocorre é muito significativo, pois neste mesmo momento histórico temos o surgimento da Informática, a ampliação do numero de cientistas e, consequentemente, do numero de pesquisas e ainda proliferação de novos conhecimentos, descobertas e invençóes.

Assim, os acontecimentos que gestaram a Ciência da Informação podem ser assim representados:

- avanço científico e tecnológico, principalmente em função da $2^{\text {a }}$ guerra mundial e, consequentemente a «explosão bibliográfica»;

- necessidade social, cultural e politica do registro e transmissão dos conhecimentos e informaçóes, produto do processo de desenvolvimento da ciencia e da tecnologia;

- surgimento de novas tecnologias, tais como o computador e o microfilme. (Pinheiro, 1997,p.72)

Esta origem marca profundamente a Ciência da Informação, no sentido que a mesma, até a atualidade ainda mantém forte relação com as temáticas deste momento inicial e com as tecnologias aplicadas ao equacionamento do caos bibliográfico, sendo que inicialmente, nos referimos ao microfilme e atualmente, as diferentes aplicaçóes relacionadas as tecnologias de informação. 
A partir destas considerações podemos afirmar que, a Ciência da Informação é um dos produtos do desenvolvimento cientifico e tecnológico e que a mesma objetiva, em seu momento inicial, gerar uma ordem no caos bibliográfico que então reinava no contexto científico, por meio da organização e tratamento da informação gerada e registrada.

A compreensão histórica da origem da Ciencia da Informação, deve ser extrapolada no sentido de que um conhecimento epistemologico mais amplo exige um olhar mais aguçado. Concordamos com Bachelard (1996,p.71) quando este filosofo afirma que «o historiador da ciencia deve as idéias como se fossem fatos. O epistemólogo deve tomar os fatos como se fossem idéias inserindo-as num sistema de pensamento. (...) Um fato mal interpretado por uma época permanece, para o historiador, como um fato. Para o epistemólogo é um obstáculo , um contra-pensamento». Tendo em vista esta postura epistemologica, indagamos: Quais as condiçóes de possibilidades da constituição de um campo de conhecimento científico voltado para o ordenamento de registros de conhecimentos cientificos por meio do uso de técnicas e tecnologias, uma vez que, conforme Japiassu(1996,p.257) na concepção classíca não havia integração entre ciencia e técnica, uma vez que a ciencia era considerada um conhecimento puro, contemplação da natureza do real sem fins práticos e a técnica era compreendido como um conhecimento prático, aplicado, visando apenas um objetivo específico, sem relação com a teoria?

Esta indagação nos possibilita avançar em tentativas de respostas que, afinal constituem-se em materia prima deste texto. A partir destas possiveis respostas esperamos refletir sobre as origens da Ciencia da Informação, bem como, sobre as relaçóes da mesma com um novo campo de conhecimento denominado de «Ètica da Informação». Vale salientar que esta reflexão se apoiará numa visão epistemológica específica para tentar avançar. Assim temos que a epistemologia pode ser compreendida como a disciplina que toma as ciencias como seu objeto de investigação relativo a reflexão sobre a genese, formação e estruturação progressiva.

Este texto está estruturado da seguinte forma: introdução (origens da Ciencia da Informação). Num segundo momento desenvolvemos uma discussão sobre a relaçáo entre a ética e a ciência. Num terceiro momento procuramos caracterizar o atual campo de conhecimento da Ética da Informação. Num quarto momento, finalizamos, retomando nossa reflexão sobre as origens da Ciência da Informação a partir de uma visão epistemologica baseada em Bachelard.

A partir destas consideraçóes iniciais, apresentamos nossas reflexôes, tendo sempre em mente que o "conhecimento do real nunca é pleno, é sempre luz que projeta sombras. Nunca é imediato e completo. Assim, o real nunca é o que se poderia achar, mas é sempre o que se deveria ter pensado». (Bachelard, 1996, p. 17).

\section{2. Ética e Ciencia}

A ciencia moderna, em sua origem, no século 17 buscava uma compreensão metódica e racional da natureza. Atualmente, devido ao acelerado processo de «modernização» via ciencia nos indagamos sobre a função desta mesma ciencia em nossas vidas. Somos cada vez mais marcados e direcionados pela ciencia e a depender dela e de suas soluçóes para nossos diferenciados tipos de problemas. Assim, os avanços científicos ocupam 
cada vez mais espaço em nossas vidas. Esta situação, nos coloca diante de uma questão importante:Como tal realidade nos afeta em termos éticos? Esta indagação deve ser feita diante do fato de que a ciencia e sua predominancia em nossas vidas nos leva a urgente necessidade de legitimarmos uma «nova moral» inteiramente independente de qualquer metafisica ou religiáo, fundamentada unicamente na racionalidade critica do homem.(Oliveira, 1993,p.155).

Visando responder a esta indagaçao acabamos por gerar uma outra indagação: Como legitimar uma «nova moral» baseada unicamente na racionalidade critica do homem, se por um lado todo o saber humano racionalmente legitimado reduz-se ao conhecimento formal, logico-matematico, ou seja, o conhecimento das ciencias fatuais que é empírico analítico. Assim, temos que considerar que, não podemos deduzir normas de fatos, ou seja não podemos, a partir do campo racional-objetivo, deduzir reflexóes e normas que se relacionam a praxis moral, pois estas situam-se no campo das ações socialmente transmitidas. Esta constatação nos coloca diante de um paradoxo, onde a humanidade, que pretende ter atingido a suprema forma de racionalidade no conhecimento dos fatos deve conformar-se a decisóes irracionais no que diz respeito a sua práxis moral.

Para ultrapassarmos esta problemática, podemos refletir sobre a «essencia do homem». Assim, temos que quem entende o homem como um ser exclusiva ou preponderantemente teórico (sujeito cognoscente), cuja unica função é pensar, irá reconhecer com válido apenas o conhecimento racional e a partir daí deixará o estalecimento de fins para a ação humana (nova moral) para o campo das açóes subjetivas. Por outro lado, quem entende o ser humano como um ser cujo fundamento se localiza no sentimento (sujeito de sentimento) e na vontade (sujeito de ação), irá reconhecer, que ao lado do conhecimento racional-dedutivo temos outro tipo de conhecimento, pois apreende o objeto de forma diferenciada. Estamos falando do conhecimento irracional-intuitivo

Assim pensado o homem é um sujeito de conhecimento cuja essencia é duplamente estruturada - conhecimento racional-dedutivo e conhecimento irracional-indutivo. Apesar desta dupla estruturaçáo, devemos salientar que o fundamento ultimo de verdade, no campo téorico é conhecimento racional-dedutivo. Neste campo a instancia final é este tipo de conhecimento, pois somente ele tem validade universal (Hesse, 1999,p.111).

Assim, a resposta para a questão sobre qual seria o impacto da ciencia em nossa eticidade, deve se orientar para o conhecimento irracional-indutivo (oriundo de um sujeito de sentimento e de ação), pois é neste espaço que se efetivam os impactos da ciencia e de seu conhecimento racional-dedutivo. Ao tecermos esta consideraçáo, estamos estabelecento a práxis humana como ponto de partida de nossas reflexóes e afirmando que a dimensão ética é imanente a própria pratica científica.

$\mathrm{Na}$ práxis humana, conforme Oliveira (1993,p.158), podemos reconhecer 3 dimensóes fundamentais do ser humano: a dimensão da vivencia subjetiva, a dimensão que se refere aos fatos do mundo objetivo e a dimensão que tem como referencia a relação do sujeito com a comunidade humana, na qual ele se encontra situado. Estas 3 dimensóes são coordenadas por 2 tipos de açóes. Num primeiro momento a ação é baseada apenas em um "cálculo de utilidade». Esta ação é denominada de racional instrumental. Numa segunda forma de coordenação temos o "consenso" sobre 
expectativas e as consequencias destas. Esta é denominada de ação comunicativa. Vale salientar que a ação comunicativa é também ação racional, uma vez que, quem age desta forma se situa numa esfera de argumentação, portanto de sociabilidade construida na base de uma racionalidade, da acareação crítica de propostas levantadas a respeito de fatos, vivencias e normas socialmente vigentes na comunidade humana concreta. (Habermas citado por Oliveira, 1993,p.158)

A partir desta compreensão, podemos considerar que, a dimensão ética é condição de possibilidade de toda práxis comunicativa (ação racional instrumental e ação comunicativa), uma vez que a dimensão da existencia humana é inexoralmente agir, pensar e sentir (sujeito cognoscente, de sentimento e de ação unificados numa pessoa humana) e nestas dimensôes se estabelece como elemento fundante a liberdade de existir e em qualquer destas dimensôes a ética é exigencia originária. Assim, a questão da relação entre a etica e a ciencia náo se resolve no nível propositivo-objetivo, pois este não é o unico nivel de linguagem, mas no nivel pragmatico-transcendental, que é fundamentalmente de natureza ética e desta forma a realação entre Ética e Ciência se dá como condição básica para uma destinação pertinente e como campo sempre atual para a ética.

Após estas consideraçôes podemos refletir sobre a ética no campo epistemológico da Ciência da Informação.

\section{3. Ética da Informação}

Conforme Capurro (2001,p.41) a Ética da Informação é a forma de reflexão sobre as possibilidades de realização da liberdade humana em contextos informacionais, bem como a troca, combinação e utilização desta informação no meio da comunicação transmitida digitalmente. De acordo com este mesmo autor a Ética da Informação, como uma teoria emancipatória, desenvolve criticas de atitudes morais e tradiçóes no campo de informação em um nível individual e coletivo. Além disso, ocupa-se da crítica do comportamento moral e da tentativa de desmascarar mitos acerca da informação e de promover um espaço de reflexão sobre a liberdade de acesso na Internet. A ética da informação está relacionada, por conseguinte, tanto à observação e a crítica da conduta social no campo da informação, quanto à investigação de estruturas de poder ou de sociabilidade dos sujeitos, determinadas por relaçóes estabelecidas por uma dinâmica informacional. Nesse sentido, segundo Capurro(2005), a liberdade de acesso está vinculada ao princípio democrático de igualdade de chances.

Conforme Japiassu (1996, p. 163 e 164), a palavra liberdade aparece como condição daquele que é livre. É uma capacidade de agir por si mesmo. Caracteriza-se como um espaço de autodeterminação, independência, autonomia. No sentido ético tem-se

que este termo relaciona-se à liberdade do direito de escolha pelo indivíduo de seu modo de agir, independentemente de qualquer determinação externa. Assim a liberdade também implica na responsabilidade do indivíduo por seus próprios atos.

O conceito de liberdade abriga uma grande multiplicidade de significados. Em essência significa uma qualidade ou valor da pessoa humana. Assim temos que Rousseau citado por Bobbio (1996), nos lembra que a liberdade resume o fato de que o ser humano, enquanto parte do todo social, náo obedece aos outros seres humanos, 
mas a si mesmo. Esta configuração libertária de Rousseau deve ser contrabalanceada pela compreensão racional de Kant citado por Bobbio (1996), no sentido de que a liberdade representaria a faculdade de fazer tudo o que se queira, contanto não se cause injustiça a ninguém. Para atingir este grau compromisso, Kant considera que a liberdade é uma vontade auto-determinada que não se baseia em impulsos sensíveis, mas tem seu fundamento nos ditames da razão. Para não deixar o ser humano refém de uma razão abstrata, Kant afirma que a liberdade é também a faculdade de só obedecer às leis externas (normas jurídicas), às quais o ser humano compreende e relaciona às suas leis internas (valores de foro íntimo).

Neste contexto de reflexáo sobre a liberdade como uma medida ética temos que considerar também os conceitos de liberdade negativa e liberdade positiva. Conforme Bobbio (1996) a liberdade negativa nos lembra, pela sua própria denominação, que algo está ausente, que algo está sendo negado e pode ser caracterizada pela situação na qual um sujeito tem a possibilidade de agir sem ser impedido, ou de não agir sem ser obrigado, por outros sujeitos. A liberdade negativa consiste em fazer (ou não fazer) tudo o que as leis, entendidas no sentido lato e não apenas no sentido técnicojurídico, permitem ou não proíbem. A liberdade negativa caracteriza-se pela ausência de impedimentos e constrangimentos para a ação do indivíduo. Por outro lado, a liberdade positiva, conforme Bobbio (1996) caracteriza-se pela autodeterminação ou ainda de autonomia, ou seja, pela possibilidade que um ser humano tem de orientar seu próprio querer, no sentido de uma finalidade, de tomar decisóes, sem ser determinado pelo querer dos outros. Neste sentido temos a definição clássica de Rousseau citado por Bobbio (1996), no sentido de que a liberdade positiva consiste no fato de que o ser humano, enquanto parte do todo social, como membro do "eu comum", não obedece a outros e sim a si mesmo, no sentido que é livre no momento em que obedece às leis que ele mesmo se deu. Ainda, neste sentido podemos relacionar a liberdade positiva como a liberdade de querer diante da presença de algo, este por sua vez, seria a comunidade.

A partir destas considerações sobre liberdade negativa e liberdade positiva somos tentados a indagar: qual a verdadeira liberdade? A liberdade negativa (liberdade individual) ou a liberdade positiva (liberdade coletiva)? Conforme Bobbio (1996), o fato de que, historicamente, a liberdade negativa seja, sobretudo um atributo do indivíduo, enquanto a positiva é sobretudo um atributo da coletividade, não significa de modo algum que, conceitualmente, as duas liberdades se distingam com base no diferente sujeito que, no final das contas, seria o beneficiário das mesmas. Assim, podemos compreender que as duas liberdades, assim apresentadas conceitualmente, se reúnem e passam a integrar uma só liberdade, no contexto da realidade. Consideramos que a verdadeira liberdade seja aquela que permita a livre expressão dos indivíduos a partir das dinâmicas normativas que fazem os diferentes contextos sociais nos quais estes vivenciam suas existências.

Estas consideraçôes sobre a Ética da Informação nos possibilitam compreender a função e a amplitude da mesma enquanto instrumento de reflexão e consequentemente de ação comunicativa (ação racional instrumental e ação comunicativa) e que uma ética da ciência é condição de possibilidade para que a ciencia possa justificar sua origem e sua dinamica, pois se neste campo de conhecimento o ser humano é sujeito 
cognoscente e de ação. Consideramos que temos aqui, sem duvida alguma, uma problemática relativa a fundamentação racional da ação humana.

\section{Consideraçôes Finais:}

$\mathrm{Na}$ introdução deste texto formulamos uma indagação: Que valores éticos podem ser observados no atual contexto epistemológico da Ciência da Informação? Poderíamos reformular esta questão é indagar novamente: Quais as condições de possibilidades da constituição de um campo de conhecimento científico voltado para o ordenamento de registros de conhecimentos cientificos por meio do uso de técnicas e tecnologias? Esta questão será objeto de reflexão neste item final.

Devemos salientar que esta reflexão tem em Bachelard um apoio fundamental, pois como este filosófo buscamos "enfrentar todo dogmatismo que fixa para sempre o seu saber, ao incorporar demonstraçôes e autoridade". (Bachelard, 1996,p.17). Neste sentido Bachelard (1996,p.17) nos adverte que "quando procuramos as condiçóes psicológicas do progresso da ciencia, logo se chega a convicção de que é em termos de obstáculos epistemológicos que o problema do conhecimento científico deve ser colocado". A noção de obstáculos é relativa a própria dinâmica de conhecer, no âmago das ciencias.Como exemplos de obstáculos epistemológicos este filosofo cita: a experiencia primeira, o conhecimento geral, o conhecimento unitário e pragmático, o obstáculo substancialista, o obstáculo animista e os obstáculos do conhecimento quantitativo. Bachelard (1996,p.18) nos informa que este fenômeno ocorre devido à dinâmica interna das ciencias, onde em suas fases iniciais faz-se presente um espírito formativo. Mas este espírito, depois de certo tempo, acaba por dar lugar ao espírito conservativo. "Chega o momento em que o espírito prefere o que confirma o seu saber àquilo que o contradiz, em que gosta mais de respostas do que de perguntas. $\mathrm{O}$ instinto consertivo passa então a dominar e cessa o cresimento espiritual". (Bachelard, 1996, p.19). Tendo em mente este conceito, buscaremos refletir sobre o espírito formativo no campo da Ciencia da Informação no sentido da presença da técnica, das tecnologias da informação e da relação destas com as intersubjetividades. A partir desta reflexão buscaremos no conceito de Ética da Informaçáo um espaço de compreensão em termos da racionalidade possivel neste campo de conhecimento.

No campo da Ciência da Informação as tecnologias da informação se fizeram presentes desde o momento formativo deste campo de conhecimento, pois neste momento (década de 60) a ciencia moderna se encontra estruturada em um sistema mundial de produção e controle com regras universalmente aceitas. Neste sistema o ordenamento é uma característica marcante, pois permite a verificação, o controle e a fixaçáo de metodologias. Todos estes elementos se relacionam a um outro elemento fundador da Ciencia Moderna - a prova científica. Ainda podemos considerar que neste contexto, a forma específica da consciência é o tecnologismo, ou seja, mais do que simplemente dizer que a técnica/tecnologia é um dos componentes da atual sociedade, estamos afirmando que a tal fenômeno constitui-se atualmente na forma de relacionamento do homem com a realidade. Podemos entáo falar de uma consciencia tecnológica 
Para avançarmos em nossa reflexão devemos, buscar no conceito de técnica uma explicaçáo para tal vinculação. Conforme ja citado anteriormente, Japiassu (1996,p.257) ressalta que na concepção clássica não havia integração entre ciencia e técnica, uma vez que a ciencia era considerada um conhecimento puro, contemplaçáo da natureza, do real sem fins práticos e a técnica era compreendido como um conhecimento prático, aplicado, visando apenas um objetivo específico, sem relação com a teoria. Ainda, podemos ressaltar que, conforme Aristóteles existem tres modos do homem estabelecer um relacionamento cognoscitivo com a realidade: por meio da teoria (conhecimento contemplativo), a práxis (onde o conhecimento serve à autogenese do homem como ser individual e político) e a poiesis (conhecimento que serve à produção de obras distintas do homem). Assim práxis e poiesis recebem sua verdade só por meio das obras que realizam (o homem ou os instrumentos), ou seja, elas possuem um fim que transcende o saber. A teoria é a forma de vida que se liberta de qualquer fim fora de si mesma e por isto realiza no mais alto grau a liberdade humana,pois ela é a dimensão do espírito subjetivo na qual a verdade emerge. Como afirma Oliveira, (1993,p.119)

"Toda a vida "pratica" e "poetica" do homem tem sua verdade no fundamento, na compreensão da totalidade, que a teoria, enquanto filosofia primeira, busca tematizar, A verdade emerge então como horizonte e fim ultimo da vida do homem, de modo que sua tematização através da filosofia significa a humanização do homem, o processo pelo qual o homem atinge a plenitude de seu proprio ser".

Por outro lado temos a visão de verdade emanada a partir dos fins da Idade Média que coloca que, a teoria é um relacionamento do homem com o real. Nesta compreensão o homem não é mais um ente entre os outros entes, mas um ente sobre os outros entes e até mesmo um ente que se contrapóe radicalmente ao mundo. Aqui temos, como passo importante, o novo conceito de ciencia proposto por Galilei onde pensar era essencialmente um movimento de mediação recíproca:o espírito produz o "projeto" de saber mediando a experiencia, já que este projeto lhe abre o horizonte de pesquisa:por outro lado, a experiencia é a mediaçáo do projeto, dado que a ela compete confirmar ou recusar sua validade científica.Daí porque a ciencia moderna é essencialmente método, ou seja, é a ligação prévia e consequente do espírito ao que ele quer saber.(Oliveira, 1996, p. 121).

Neste contexto a subjetividade produz o mundo como contexto de sentido à proporção que detém o material (o objeto) diante de si e o possui. Assim, concordamos com Oliveira (1996, p. 121) quando este filósofo coloca que "o homem moderno só se interessa pela realidade enquanto o que pode ser posto à sua disposição”. Esta posição modifica, de forma revolucionária, a auto-compreensão do homem, no sentido de que, no pensamento clássico era apenas um ente entre os outros, na modernidade torna-se o ente fundante da verdade de todas as coisas. O homem é o sujeito de tudo e todo o resto é objeto de sua ação. O homem é o centro de todas as coisas. "Assim a subjetividade só consegue realizar à medida que póe todas as coisas contra si, diante de si, isto é, enquanto ela objetiva o mundo e por isso o tonra, de fato, o campo de sua realização. Oliveira (1996,p.122). Aqui temos o surgimento da consciência tecnológica, que é a consciencia que tudo vê a partir do caráter de sujeito atribuido ao homem: técnica e auto-realização 
do homem como doador de sentido a tudo o que existe. Assim, consciencia tecnologica, conforma Oliveira (1996,p.122) é consciencia da funcionalização universal, já que a subjetividade relaciona todas as coisas a si, na perspectiva da funçáo que elas possam tem em sua auto-realização. Este é o contexto de idéias que farão surgir a ciencia moderna, onde a teoria é conceituaçáo do mundo a partir da açáo humana no mundo, não mais contemplaçáo do mundo, onde a técnica é um conhecimento pratico que possibilita um pensamento teórico devido ao surgimento da tecnologia.

Uma indagação se faz necessária: O que é realidade para esta consciencia tecnologica? Para esta consciencia só é realidade o que se deixa objetivar, ou seja, só é real aquilo que se deixa ser usado pelo homem em seu processo de auto-realização, só o que é dominável pelo homem em função de si mesmo. A relação sujeito-objeto é a polaridade característica da consciencia tecnologica, e tudo é visto a partir desta polaridade (Oliveira, 1996, p.122). Assim, a consciencia tecnologica cria o tecnologismo. Com esta afirmação não se pretende simplesmente dizer que o mundo o atual mundo do homem tem como um de seus constituintes fundamentais os instrumentos técnicos, ou seja, frutos da técnica e da tecnologia, mas antes, estamos afirmando que o próprio relacionamento do homem com sua realidade é tecnológico.

Assim, a partir destas consideraçóes temos que, as condiçóes de possibilidade de constituição de um campo de conhecimento como a Ciencia da Informação dá-se, de forma, preponderante junto a tecnologia devido ao fato de que esta surge com a missão de tornar possivel a aplicação dos conhecimentos científicos. Agora temos não apenas a ciencia, mas a ciencia aplicada que busca conscientemente ir além da experimentação gerando produtos e serviços de natureza cientifica e tecnologica e, assim fazendo, transforma a realidade em potencia, ou seja, o que é real é o que virá e virá por meio da tecnologia que se estrutura por meio da ciencia e que, num movimento circular, possibilita esta mesma ciencia. Assim, a Ciencia da Informação é espaço de efetivação da consciencia tecnologica, como toda ciencia moderna e de forma específica desenvolve-se neste contexto científico o tecnologismo, ou seja, no contexto da Ciencia da Informação a relação entre o fenomeno informacional e seu usuário é perpassada pelas técnicas de representação e recuperação da informação e,cada vez mais e de forma inexorável, pelas tecnologias de informação.Neste sentido, a Ciencia da Informação não está sozinha, uma vez que, "a vida humana, em toda sua dimensionalidade é cada vez mais submetida a condicionamentos da razão tecnologica:toda a organizaçáo do trabalho e da economia, o sistema de educação, a rede de comunicaçóes, os instrumentos financeiros, o sistema de defesa e o próprio Estado”.(Oliveira, 1996,p.125)

A questão que emerge neste momento é apenas uma: o relacionamento de objetivação (inerente a consciencia tecnologica) é o relacionamento adequado às subjetividades? Conseguirá um campo de conhecimento científico ultrapassar sua condição original ( o tecnologismo) e avançar no sentido, de incorporar as subjetividades, a reciprocidade das consciencias e construir um sistema institucional de liberdade? As respostas a estas questôes podem se dar por meio de diferentes conteúdos, entretanto consideramos que quaisquer que sejam tais respostas, ela deverão, como condição fundante de sua lógica discursiva, incorporar reflexôes de natureza ética, uma vez que neste campo de conhecimento torna-se possivel erguer a voz, não contra a técnica e o tecnologismo, mas contra a técnica que se faz irracional por não perceber sua funcionalização à dialética do reconhecimento das liberdades. Contra o tecnologismo que reduz a capacidade criadora humana em simples combustivel para gerar energia para os sistemas ainda em 
funcionamento. Contra a consciencia tecnologica que reduz e impede as subjetividades a produtos, negando historicidade e pertinencia historica às mesmas.

A partir destas consideraçoes, pensamos que a Ética da Informação constitui-se num campo de reflexôes que inauguram a presença da pessoa humana no campo da Ciencia da Informação, na condição inerente de consciencia subjetiva e transcendental e da informação como fenomeno humano e como tal indissociável da busca de liberdade. Neste sentido da Ciencia da Informação deve compor com o grupo das ciencias interpretativas, onde o fenomeno da auto-genese do homem é foco central e a delimitação do objeto de estudo não é fim, mas meio para novas indagaçóes.

\section{Referências bibliográficas}

BACHELARD, Gaston. A formaçao do espírito científico:Contribuição para uma psicanálise do conhecimento. rio de Janeiro:Contrponto, 1996. 316 p.

BOBBIO, Noberto. Igualdade e Liberdade. Torino: Ed. Einaud, 1996.

CAPURRO, Rafael. O Crescimento mundial da rede digital leva a uma ética global da informação? In: Revista Internacional de Teologia: Ciberespaço, Ciberética, Ciberteologia, v. 1, n. 309, p. 38-49, 2005.

. Ética para provedores e usuários da informação. In: Orgs. Anton Kalb, Reinhold Esterbauer e Hans-Walber Ruckenbauer. Cibernética - Responsabilidade em mundo interligado pela rede digital. São Paulo: Loyola, 2001.

Epistemology and Information Science. REPORT TRITA-LIB-6023.

Ed. Stephan Schwarz, agosto, 1985. (capturado da Internet em 08 de junho de 2001 via Disponível em: <http://v.hbi-stuttgart.de/ -capurro/trita.htm>.

HESSE, Johannes. Teoria do Conhecimento. São Paulo:Martins Fontes, 1996.

JAPIASSU, Hilton, MARCONDES, Danilo. Dicionário Básico de Filosofia. $3^{\text {a }}$ ed. Rio de Janeiro: Jorge Zahar Ed.1996.

OLIVEIRA, Manfredo Araújo de. Ética e Racionalidade Moderna. São Paulo: Loyola, 1993, (Coleção Filosofia; 28), p. 22.

PINHEIRO, Lena Vania Ribeiro. A Ciência da Informaçáo entre sombra e luz:Domínio epistemológico e campo intersdisciplinar. Rio de Janeiro: UFRJ, 1997. (Tese de Doutorado em Ciência da Informação). 